\title{
Attitudes towards migrant workers in South Africa: A critical discourse analysis
}

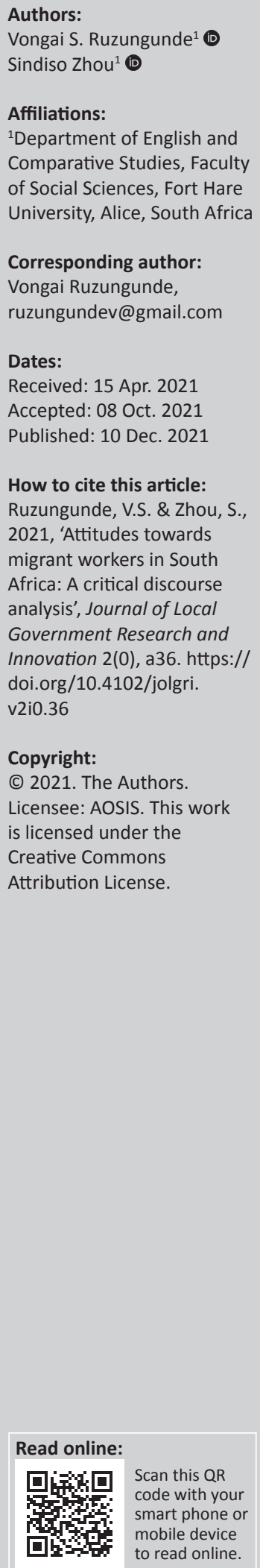

\begin{abstract}
Background: The influx of migrants from neighbouring countries has contributed to diversity in South Africa. This has caused on-going clashes between local residents and migrants. This article explores the role of discourse towards enabling a cohesive society. There has been much focus on migrants working in South Africa over the 2020 December festive season as many faced challenges in travelling to their respective countries because of the COVID-19 pandemic. This limelight exposed the underlying discrimination towards migrants in South Africa remain regardless of the South African progressive Constitution that values and respects individuals as well as protecting them from discrimination.
\end{abstract}

Aim: This article adopts threat theory and uses critical discourse analysis to highlight the existing and continued discrimination towards migrant workers. The article exposes the causes of social inequalities, which can assist the government in decision-making towards reducing the inequality gap in service delivery.

Setting: Public viewer comments on the news updates on migrants' travel that were posted on the national news websites over the 2020 festive season were analysed.

Methods: Critical Discourse analysis (CDA) was employed as a method of analysis in this article.

Results and conclusion: The article intends to add to the existing body of knowledge and to also inform local government towards canvasing agenda that incorporate all human rights and enable a cohesive society by considering the role of discourse as an enabler of the problems experienced in societies. The results show that discourse contributes to negative attitudes, hate speech, discrimination and stereotyping towards migrants in South Africa.

Keywords: migrant workers; critical discourse analysis; diversity; attitudes; labour migration.

\section{Introduction}

South Africa (SA) is often referred to as a rainbow nation because of its diverse nature. Diversity in SA can be witnessed through the different ethnic groups and different official languages that the nation has embraced. In South Africa, four major ethnic groups, namely the Sesotho-Setswana, the Nguni (which consists of Zulu, Xhosa, Ndebele and Swazi), the Venda and the ShangaanTsonga group, make up the majority of the Black population (South Africa's Diverse Culture Artistic and Linguistic Heritage 2020). The South African population also comprises the white population with the majority (60\%) being Afrikaans speaking and the remaining $40 \%$ being English speakers (South Africa's Diverse Culture Artistic and Linguistic Heritage 2020). The South African population also comprises mixed-races, who have a mixed lineage. There are 11 official languages in South Africa namely English, Afrikaans, Ndebele, Sepedi or Northern Sotho, Xhosa, Venda, Tswana, Zulu, Southern Sotho, Swazi or Siswati and Tsonga (South Africa's Diverse Culture Artistic and Linguistic Heritage 2020).

To compound the diversity challenge, SA has embraced different nationalities within its boundaries as evidenced by the migration of many individuals mostly from the neighbouring countries such as Zimbabwe, Mozambique, Malawi, Zambia and so on, in pursuit of better opportunities for economic advancement (ILO Report 2019). According to Mukumbang, Ambe and Adebiyi (2020), an estimated 2 million foreign-born migrants of working age (15-64) were living in SA in 2017, representing 5.3\% of the South African labour force, and to date, the foreignborn migrant population in SA is estimated to be around 4.2 million (Garba 2020). For this article, focus is on the diverse nature of SA in relation to migrants.

South Africa is an attractive destination for people escaping their home countries in the pursuit of a more dignifying and humane survival because of its commitment towards upholding human 
rights and the rights of foreign migrants. The South African economy is one of the most advanced economies in Africa and it has made a notable contribution with regard to the influx of migrants from other countries. The extraordinary flow of migrants into SA has put the South African government in a challenging position with regard to its stand to comply with its pledge towards upholding human rights, whilst at the same time delivering its promise to uplift the socioeconomic welfare of its citizens. The South African government is also faced with challenges in trying to balance delivery of its promises towards its own citizens as the nation still fights in reducing socio-economic gaps created through apartheid, such as racial discrimination (Garba 2020). Regardless of the political will and efforts by the government to accommodate migrants in SA, the increasing economic and financial hardships in the country have led to the government implementing and often adjusting laws that impact negatively on the lives of foreign-born migrants in multiple ways (Mukumbang et al. 2020).

The 2030 Agenda for Sustainable development of the International Labour Organisation (ILO 2019) acknowledges the positive impact of migrants towards inclusive growth and sustainable development and also places focus on achieving decent work as one of its goals. The objectives to be achieved under the decent work goals include: (1) empowering migrants and societies to realise full inclusion and social cohesion, (2) minimise the adverse drivers and structural factors that compel people to leave their country of origin and (3) facilitate fair and ethical recruitment and safeguard conditions that ensure decent work. Of significance to the ILO's decent work and fair migration agendas is also the target 8:8 'protect labour rights and promote safe and secure working environments for all workers, including migrant workers, in particular women migrants and those in precarious employment'.

A report by the World Bank (2018) revealed that migrants had a positive impact on jobs and wages in SA. The report highlighted that migrants are highly entrepreneurial, with most being self-employed, which carries a positive effect on the economy as their entrepreneurship, if successful, also provides multiplier effects in the South African economy. According to the World Bank Report (2018), migrants and locals can hold jobs that complement each other instead of competing. By exploring the role of discourse in enabling negative attitudes, this study intends to contribute towards local governance by highlighting the role discourse can play in administration and policy implementation towards changing the current narrative. The government needs to highlight the job opportunities that exist and discredit myths and participate in discourse and policymaking that mirrors a more complex reality than the 'theft of local jobs' by migrants and refugees.

The social and economic inequalities that exist within the SA economy coupled with issues such as institutionalised racial discrimination pose challenges for foreign migrants as the local citizens' frustrations can be channelled towards them regardless of the government's efforts to uphold human rights for both locals and foreigners (Mukumbang et al. 2020). Economic frustration, joblessness and competition over scarce resources are foundations often used to create a setting that can give rise to anti-migrant sentiments and attitudes. Many South African workers seem to consider foreign co-workers to be responsible for low wages and poor working conditions as supported by many managers' claims that foreigners are willing to work hard at low costs (Di Paola 2013; The New Humanitarian 2020). In some cases, South African nationals often ascribe the economic frustrations, joblessness and the competition over scarce resources in $\mathrm{SA}$ as the foreign migrants' responsibility (The New Humanitarian 2020). This breeds negative sentiments towards foreign migrants from the South African nationals. As such, foreign migrants may be subject to prejudice, discrimination and unfair experiences regardless of the South African government's efforts to uphold human rights across all levels (Garba 2020).

Many studies have focused on assessing attitudes towards migrants in SA through different dimensions including focusing on the four dimensions of attitudes towards foreigners based on social tolerance, interpersonal trust, employment preference and attitudes towards migrants. Some of these findings (Cozien 2015; Garba 2020; Schippers 2015) revealed intolerance from South Africans towards foreigners, growing levels of distrust amongst South Africans towards foreigners. Conversely, some findings also revealed the shift in the mindset of some South Africans from previously held mentality that employment preference is to be awarded to South African citizens over foreigners as more individuals are becoming either neutral or dismissive about the awarding of preference. Some of the studies (Masuku 2020) also revealed that South Africans were fostering positive attitudes towards migration although the greatest portion of respondents agreed that foreigners are to be allowed into SA on the condition that certain criteria are met. Evident in all the studies, are the negative attitudes held towards migrants. Whilst many studies have been conducted on attitudes towards migrants, studies that focus on the role of discourse in perpetuating these attitudes are rare. This article addresses the identified gap by exploring the role of discourse in the continuous enactment of negative attitudes and how it can be used to enable social cohesion.

As a result of the lockdown restrictions implemented following the coronavirus disease 2019 (COVID-19) pandemic outbreak in early 2020, the December 2020 holidays were met with commotion as people travelled to their respective homes after a long time without spending time with their loved ones and families. The easing of these restrictions to accommodate travel brought much limelight on migrants as they travelled to their respective homes (places of origin) for the festive season and the border posts were abnormally congested. The discussions around the congestion and suffering experienced during this period brought to light subtle issues that still exist in terms of migrants and local citizens' relations. This 
article contributes to the existing body of knowledge in local governance in understanding the role of discourse in the continued tensions in relations with and sentiments towards migrant workers by South African nationals. The article also carries a significant contribution for local government administration as it focuses on exposing some of the root causes of social inequalities, which can aid the government in making more informed decisions in the fight to narrow the inequality gap in service delivery across all spheres.

\section{Definition of key terms}

Migrant:

$[A] \mathrm{n}$ umbrella term, not defined under International law, reflecting the common lay understanding of a person who moves away from his or her place of usual residence, whether within a country or across an international border, temporarily or permanently, for a variety of reasons. (International Organization for Migration 2019:132)

\section{Methodology}

Critical discourse analysis (CDA) was employed as a method of analysis in this article. The CDA approach has its base on language and text being influencers of how values and perceptions are enacted and reproduced in people (Van Dijk 2006). The CDA approach concentrates on analysing the veiled structural connections of supremacy, discrimination, power and control as revealed in language (Van Dijk 2006). It preserves the outlooks that society contributes significantly in the way language, text and communication are moulded, designed and understood and how these impact values, ethics, morals, views and perceptions of different concepts. The CDA approach intends to make discourse more noticeable and translucent within societies as it is regarded as a blurred object of power. Lexical analysis, one of Fairclough's (1995) methods of analysis was used to analyse public viewers' comments on the news headlines that were broadcasted focusing on migrant travel during the festive season of December 2020. Fairclough's (1995) model for CDA consists of three processes, which are inter-related and linked to three inter-related dimensions of CDA, namely the object of analysis, the process on which the object is produced and the socio-historical conditions, which govern the processes. In lexical analysis, text is analysed with focus on description, processing is also analysed with focus on interpretation and lastly there is also social analysis focusing on explanation. This approach enables focus to be placed on the signifiers that make up the text, the specific linguistic selections. This approach acknowledges that the choice of text or utterances is tied to the conditions of possibility of that utterance. Texts are instantiations of socially regulated discourses and the processes of production and reception are socially constrained. The news articles used in this paper were obtained online on one of the main and official websites of the public broadcaster, South African Broadcasting Corporation News, which provides news from within and across the world to the South African nation. Focus was on the news articles that were published during the festive season mainly between 23 and 27 December 2020 when the issues at the different border posts in particular, the Beitbridge border post. In this regard, the sampling was purposive.

The news website and its official Facebook page are public platforms, which allow for viewers to publicly express themselves on any issue published on the page. It allows for some validity in analysing as actual views can be observed from the interactions amongst viewers and viewer comments on the platform.

\section{History of migration}

The migration of people from southern African countries into SA dates back to the 1800s (Consortium for Refugees and Migrants in SA 2008). It can be noticed that the migration of Black migrants has been a part of the South African urban and rural areas for over a century (Peberdy n.d.). Foreign migrants have lived in SA as contract workers, documented and undocumented migrants, contributing to the construction of the South African economy into one of the strongest in the region (Mukumbang et al. 2020). Most migrants have functioned as circular migrants retaining homes and families in their countries of citizenship, with others having established other family ties in SA too (Peberdy n.d.).

Labour migration is one of the main influencers of migration into SA. The industrial development in SA and its strong economic position in the continent are the magnets attracting high volumes of migration for both skilled and unskilled labour migrants from within the region and across the globe, in pursuit of work opportunities in the mining, manufacturing and agricultural industries (Office of the United Nations High Commissioner for Refugees, Global Trends 2013). South Africa is also considered to be the easy mediator and stepping stone for migration to Europe and America, hence most foreign migrants will opt to relocate to SA first en route to countries abroad.

According to a report by the Office of the United Nations High Commissioner for Refugees, Global Trends (2013), over 4 million migrants (excluding irregular migrants) were recorded in Southern Africa in the year 2013, with SA holding the largest number of migrants (2.4 million including 1.5 million from Zimbabwe) within its borders.

According to the African Centre for Migration and Society (2020), a legal migrant who possesses the same qualifications, age, gender and belonging to the same 'population group' and residing in the same place as a South African citizen, has a higher prospect of being employed than a South African. As such, within most communities in SA where migrants reside and work, the conception held is that foreigners deprive South Africans of employment and other business opportunities and therefore pose a strain on the limited social services and amenities (Masuku 2020). These conceptions held in turn constitute the main drivers of xenophobia and 
other related experiences of foreign migrants in SA (Choane, Shulika \& Mthombeni 2011; The New Humanitarian 2020).

\section{Migrants issues Documentation}

Some of the benefits awarded to foreign migrants include the right to study, work (where certain skills are required), access to medical services within SA. These benefits may have contributed to the influx of migrants into the Republic of South Africa. The large number of entries into the republic make it difficult for the government to regularise the national asylum system (Mukumbang et al. 2020). Other challenges such as administrative inefficiency and corruption added on to the mounting pressures in trying to deal with the volume of migrants, results in backlogs in processing and adjudication of documents, leaving some to stay without documentation or be forced to search for survival as undocumented migrants (Masuku 2020).

\section{Exploitation and abuse}

Many migrants in SA find themselves undocumented and residing illegally as they flee their countries in pursuit of better living conditions in SA. As a result of the large numbers of migrants entering SA, the government finds it difficult to match up the long queues and filing in paperwork for the documentation of all migrants (Mukumbang et al. 2020). Out of desperation, most find themselves looking for employment without proper documentation. According to Di Paola (2013), it has become a norm amongst employers that foreign migrants work hard for less and as such they become vulnerable to exploitation and abuse working below the minimum wage out of desperation. This can also be evidenced in the domestic worker industry. A report by the ILO (2013) showed that many of the domestic workers in SA homes were migrants and mostly undocumented migrants, which increases their exposure to exploitation, abuse and poor working conditions. Many migrant workers are found in low and semi-skilled positions, which are often physically demanding and involve dangerous working conditions in terms of non-respect of minimum wages, withholding of wages, illegal deduction of fees and costs from migrant workers' wages, excessive working hours, insufficient lunch breaks, daily, weekly and holidays' rest periods, no payment of overtime and annual leave, withholding of passports and other identity documents, unjustified demands to carry out tasks other than those specified in the contract and unjustified terminations (ILO 2019).

\section{Unequal access to services}

The social support structure for migrants in SA is relatively weak as compared with the native nationals (Business Insider South Africa 2020). The inequalities in social support structures were further revealed in the addressing of COVID-19 pandemic containment measures. Different economic and hunger alleviation measures were implemented in an effort to address some of the socio-economic hardship that the COVID-19 pandemic has left on the nation. Most foreign migrants were not included in the relief grants offered by the government yet they are also affected. Most of these businesses are owned by asylum-seekers, refugees and undocumented migrants (Mukumbang et al. 2020). Although their operations are equally affected by the COVID-19 crisis, they are not considered for the Business Relief Fund as they are automatically excluded based on the qualification criteria, which emphasises that businesses must be 100\% South African owned, with at least $70 \%$ of employees being South Africans and also recipients must be tax compliant (Mukumbang et al. 2020). According to Business Insider South Africa (2020), some migrants employed in the formal sector and who were paying the necessary taxes before lockdown measures were imposed, did not receive their UIF (Unemployment Insurance Fund) payments whilst the South African workers received their UIF, with the argument being that the system used by the UIF to process payments does not recognise foreign passport numbers.

\section{Xenophobia and negative social attitudes}

The migration process has a bearing on both the native and the migrant population. According to Schippers (2015), the effects of the migration process can be seen in the different views and attitudes held by the native population towards the migrants and these can be negative or positive.

Negative attitudes towards foreigners have been nurtured across the world where the rise of xenophobia directed towards migrants has been one of the more unambiguous displays (Carter 2010; Schippers 2015). According to Adam and Moodley (2013), 62 individuals (41 migrants from around Africa and 21 SA nationals mistaken for foreigners) were killed by mob groups across SA. May 2008 marked significant anti-migrant violence in SA according to the Mail \& Guardian (2008) as cited by Schippers (2015).

Violence against foreigners continued in SA as evidenced by the 2013 occurrence in the Zamdela Township in Sasolburg (Adam \& Moodley 2013). There were protests initiated after residents displayed their dissatisfaction with regard to a proposed merger between two municipalities by looting foreign-owned shops.

As cited by Schippers (2015), the Mail \& Guardian (2008) contended that the violence enacted on foreigners in SA was a response to the perceptions held by the South African nationals that foreigners take away their job opportunities. A report by the International Organization for Migration (2009) on the 2008 xenophobic attacks stated that the use of violence against foreigners was a means used by South African citizens to reduce their competition for resources by sending foreigners away from their country.

A recent example of attacks against foreigners was witnessed in July 2020 when SA truck drivers protested against the employment of foreign nationals, shutting down roads and setting trucks on fire resulting in fatalities in the process (SABC News 07 July 2020a). 
The reason South Africans foster xenophobic and negative sentiments towards foreigners has gathered much attention since the violence in 2008.

\section{Integrated threat theory}

Integrated threat theory proposed by Stephan and Stephan (2000) has its basis on explaining the aspects of alleged threat that can result in prejudice between social groups. This theory is applicable to any social group that may feel susceptible to mistreatment in one way or the other by another group in the same space. The integrated threat theory deals with perceived threat not actual threat (Stephan \& Stephan 2000). Perceived threat involves any threat that the members of a group can assume or believe that they can encounter from the other group (the threat) regardless of the existence or non-existence of those threats. An example relevant to this article would be the feeling held by local South African citizens that migrants from other countries take their jobs, as evidenced by the attack on foreign truck drivers in July 2020 (SABC News 07 July 2020a). These perceptions held against the group perceived as a threat can result in prejudice amongst groups, which is often manifested in stereotypes and negative attitudes held towards migrants in this case. The Integrated Threat Theory envisages that undesirable pre-set verdicts about another group can result in prejudice and this prediction is based on research that established links between higher levels of prejudice towards a stereotyped group and the beliefs held in negatively rated stereotypical traits (Stephan, Ybarra \& Morrison 2009).

\section{Discussion and analysis}

News on migrant travel made headlines over the 2020 festive season. Much news revolved around the challenges faced at the main border posts, as travellers found themselves stranded in long queues, congestion at the borders and roads leading to the borders. Much focus was on the Beitbridge border post which is one of the main border posts that link SA with other countries and is used for economic travel purposes and leisure for Zimbabwean residents and those travelling to Malawi, Zambia and Democratic Republic of Congo. The headlines trending on the news included 'Calls for intervention at the Beitbridge border as several die in congestion' (SABC News 26 December 2020d), 'Cross border travel: Thousands stuck at Beitbridge waiting to cross into SA' (SABC News 06 January 2021), 'Truck drivers frustrated as they remain stuck at the border' (SABC News 25 December 2020c), 'Four truck drivers have died at Beitbridge Border post' (eNCA news 24 December 2020). On the different news headlines posted on Facebook on South African Broadcast News pages and videos of the proceedings at the border post, viewers would express their views with regard to the situation in the comments section. It is these comments that were analysed for this article employing Richardson's (2007) different methods of analysing newspapers as applicable. Richardson (2007) proposed different ways of analysing text that vary from syntax, modality and transitivity analysis (these place emphasis on sentences and the construction of
TABLE 1: Viewer comments on migrants situation in South Africa.

\begin{tabular}{|c|c|}
\hline Theme & Statements aligning with theme \\
\hline $\begin{array}{l}\text { Negative other representation } \\
\text { and positive-self representation }\end{array}$ & $\begin{array}{l}\text { - 'I know some are bad, but we can't paint all } \\
\text { with the same brush. I have met good foreign } \\
\text { people' } \\
\text { - 'They were supposed to stay in their own } \\
\text { country, when we said they overpopulated our } \\
\text { South Africa they said something about hatred! } \\
\text { We don't care!' }\end{array}$ \\
\hline Presupposition & $\begin{array}{l}\text { - 'Lesson learnt, stay in your own country to } \\
\text { avoid such' } \\
\text { - 'We can't continue to take care of foreigners. } \\
\text { We are also tired and have enough problems. } \\
\text { They must not come back' } \\
\text { - 'Perhaps they will learn to remain in their own } \\
\text { countries and build conducive environment to } \\
\text { strengthen African economy' }\end{array}$ \\
\hline Foregrounding & - 'They deserve what they are facing' \\
\hline Naming and referencing & $\begin{array}{l}\text { - 'Perhaps they will learn to remain in their own } \\
\text { countries and build conducive environment to } \\
\text { strengthen African economy' } \\
\text { - 'They were supposed to stay in their own } \\
\text { country, when we said they overpopulated our } \\
\text { South Africa they said something about hatred! } \\
\text { We don't care!' } \\
\text { - 'We are not going anywhere. Death is } \\
\text { everywhere' } \\
\text { - 'Fact is people are dying at the border and it's } \\
\text { sad. We all deserve to live' } \\
\text { - As much as Zimbabwe and South Africa } \\
\text { sometimes don't see eye to eye at the end of } \\
\text { the day we are one } \\
\text { trying to show us that Africa should trade and } \\
\text { create its own economy without involving } \\
\text { countries such as China etc. } \\
\text { - These poor people. Something needs to be } \\
\text { done urgently to move them through the } \\
\text { border, before there is a tragedy. Also food, } \\
\text { water and shelter... and medical care. } \\
\text { Allowing a situation such as this to develop } \\
\text { when so many are dying of CoviD-19 is } \\
\text { criminal }\end{array}$ \\
\hline Multimodal & Laughing face reactions on the headlines \\
\hline
\end{tabular}

Source: SABC News, 2020a, 'Truck drivers once again protest the employment of foreign nationals, forcing the closure of a major Cape Town highway', 07 July, viewed 07 February
2021, from https://www.youtube.com/watch?v=p01dDpQdZPA; SABC News, 2020b, 2021, from https://www.youtube.com/watch?v=p01dDpQdZPA; SABC News, 2020b,
'Discussion on bottleneck at the border post', 25 December, viewed 07 February 'Discussion on bottleneck at the border post', 25 December, viewed 07 February
2021, from https://www.youtube.com/watch?v=m-Dsckyzn4o; SABC News, 2020c, 2021, from https://www.youtube.com/watch? $v=m-D s c k y z n 40 ;$
'Truck drivers frustrated as they remain stuck at the border', 25 December, viewed 07 February 2021, from https://www.sabcnews.com/sabcnews/truck-drivers-frustrated as-they-remain-stuck-at-beitbridge-border/?fbclid=IwAROqrXcRvcAwjMV8IKTjfOdKy7M 3_7w2-4anJJLD_dw6PewrRXbqjBcnCps.

propositions in sentence structuring), lexical analysis (analyses words with emphasis on the structuring of propositions) (see Table 1).

\section{Analysis of public viewer comments on the news headlines}

\section{Negative-other representation and positive-other representation}

The hate against my foreign brothers is real, death could have been avoided by all means. Some of your comments are unnecessary. I know some are bad, but we can't paint all with the same brush. I have met good foreign people. (SABC News 2020a)

The given statement was a comment by one of the viewers after observing most of the comments made by others in respect of the situation faced by migrants at the border post. This comment suggests that most of the comments carry negative attitudes towards migrants hence saying 'the hate against my foreign brothers is real'. Acknowledging that 'some are bad' presupposes the negative-other representation is true as it suggests that migrants are associated with doing bad and 'we can't paint them all with the same brush' presupposes that although they are associated with bad, but 
if room is given, a few good can be picked from 'them', which refers back to uniformity and stereotyping. The given statement also demonstrates foregrounding, which focuses on making conclusions of a person based on what has been put on the foreground:

They were supposed to stay in their own country, when we said they overpopulated our South Africa they said something about hatred! We don't care! (SABC News 2020b)

Van Dijk's ideological square concept as explained by Richardson (2007) can be observed in the given statement. Positive self-representation and negative-other representation are characteristics of the ideological square. Outsiders are represented in a negative way whereas insiders are portrayed in positive way. The given statement shows emphasis on negative characteristics towards migrants as sentiments are echoed, which show that migrants are overpopulating SA and if 'they' stay in 'their countries' then SA would not be overpopulated.

in addition, the use of words such as 'they' 'our' 'we' highlights how migrants are associated with a certain social status or group, which is different from the one for South Africans as they refer themselves as 'we' and migrants as 'them'. According to Blommaert (2005) in Richardson (2007), the use of such terminology signals intended social meanings.

\section{Foregrounding}

'They deserve what they are facing' (SABC News 2020c) Foregrounding can also be observed in this statement. Migrants are viewed in negative light and as such, there is no empathy towards the situation that they are facing and conclusions and judgements are made in negative view. This highlights the social values held by some with regard to migrants.

\section{Naming and referencing}

Perhaps they will learn to remain in their own countries and build conducive environment to strengthen African economy. (SABC News 2020a)

The naming and referencing using terms such as 'they' 'their' highlights that migrants are viewed in uniformity and suggests a stereotype associated with migrants. The statement also presupposes that the migrants deserve the suffering experienced at the border and this will make them to stay in their own country and focus instead on developing their home country instead of thinking about returning to SA, which signals some relief for South African citizens.

'Fact is people are dying at the border and it's sad. We all deserve to live' (SABC News 2020c) the referencing used in this sentence suggests oneness. It echoes the sentiments of one who understands that whether migrant or non-migrant, 'we' all deserve to be treated fairly and with dignity and no one should suffer because of their nationality:
Lesson learnt, stay in your own country to avoid such. (SABC News 2020a)

This comment was made by one individual following the news that many were dying at the border because of congestion, excessive heat and no sanitation and resources. It can be observed from the comment that the statement carries negative attitudes towards migrants as the viewer who made the comment strongly believes that the migrants dying at the border are learning their lesson by undergoing the unsettling conditions faced at the border during the festive season, which will make them aware that they should not come into SA. The statement presupposes that the migrants deserve what they are experiencing and maybe by going through it they will learn to stay in their countries and not return to $\mathrm{SA}$.

There was unrest on the comment section as it also became a war zone with some migrants responding and fighting back on some of the comments. In response to the given statement, one viewer commented 'We are not going anywhere. Death is everywhere' the statement in the response 'we' suggests that the respondent is a migrant as they responded in counter attack to a comment that suggested that migrants should return to their home countries.

'We can't continue to take care of foreigners. We are also tired and have enough problems. They must not come back' 'Why can't they boost their own economy instead of painting other people's houses when yours is a mess' (SABC News 2020c) to which others responded asking if they had physically taken care of a foreigner. This statement and counter statements presupposes that local South African citizens view migrants as burdening their economy in line with some literature (Garba 2020; Masuku 2020), which highlights that local citizens negatively assume that migrants are responsible for unemployment and shortage of resources in SA. Some migrants commented on the Facebook platform that they were paying taxes and boosting the economy of SA and other local South African citizens responded back saying they should boost their economy instead.

\section{Multimodal analysis}

On the SABC news webpage on the Facebook platform, there is also an option to react with an emoji-image to any news posted. These images range from faces showing happiness, laughing face, a like button, angry face (a person chooses to react with the image that best describes his or her feelings to the post). With regard to the news posted about the challenges encountered by migrants in travel, there are a number of viewers who reacted with a laughing image to the post. According to Kress and Van Leeuwen (2001)'s analysis of images under the Multimodal Critical Discourse analysis (MCDA), discourse can also be communicated through images, which are often by passed in our everyday lives but carry messages (Dicks 2019). As can be observed in this case, a person reacting with a laughing image to a story 
portraying suffering can be interpreted as having no remorse and in this case, hints on elements of hate existing towards migrants.

Some of the migrant travellers who were interviewed by the SABC News, 26 December 2020d expressed their frustrations regarding the economic situation in their home country and emphasised that they would rather endure the long queues and congestion as they pursue better living conditions.

In news broadcasted by the NewzRoom Afrika, 06 January 2021, the footage revealed people in long queues, other sitting down showing signs of fatigue and others sweating. A few who were interviewed expressed their concerns with the lack of adherence to social distancing or any of the measures implemented to fight the COVID-19 pandemic. Others raised frustrations regarding the lack of more personnel to assist at the border posts as the government knew that people would be travelling.

The SABC News (2020d) had an interview with the parliamentary portfolio committee on 25 December 2020. The representative highlighted that the committee had taken measures to make the situation better, such as the local municipality to provide sanitation and water at the border points and the Department of Home affairs also increased personnel at customs and also proposals for a one stop shop implementation in the 2021 calendar.

The views of political leaders on the issues around migrants in SA were also sought to enhance a wide base of information. In an online IOL News (2020) article with the headline 'Xenophobic South Africans can't champion \#BlackLivesMatter-Malema' Julius Malema the leader of the Economic Freedom Fighters (EFF) political party expressed his concerns over some South Africans' support of the \#BlackLivesmatter global movement whilst remaining silent on the attack of foreigners:

Whilst you kill Zimbabweans, Mozambicans, Nigerians and Somalians here in South Africa and you call them "makwerekwere" and all sorts of names, today you are holding a placard saying \#BlackLivesmatter? You supported the killing of your fellow brothers and sisters, ... that is narrow nationalism. (IOL News 2020)

The given statement made by the EFF leader reveals some of the negative actions of local South African citizens towards migrants. In the statement, the EFF leader is clearly against the attacks and discrimination towards foreign nationals by local South African citizens.

'We are one family. Borders were imposed on us' in this statement, it can be observed that the political leader is advocating for oneness and unity. With their influence, political leaders can play a major role to advocate for change in perceptions and hate towards foreign nationals.

\section{Findings}

The results reveal that discourse does contribute to the continued evidence of negative attitudes manifested in hate speech, discrimination and stereotyping in many individuals towards migrants in SA. The echoing of these sentiments on a public platform can be leeway to the reproduction, reinforcement of such attitudes to others through these open platforms. The results show that many of South Africans believe that their economy is being weighed down by foreigners and if they were to return to their countries, then things would be better for them. These findings confirm with the works of Mukumbang et al. (2020) and Schippers (2015). Major themes emerging from the results through discourse were negative attitudes and stereotyping.

\section{Negative attitudes}

Based on the comments from the comment section of the news report on Facebook, it was observed that many individuals felt that the migrants deserved the harsh conditions that they were facing at their border posts as a result of congestion and long queues at the border posts. Others felt that the borders were supposed to be opened for the migrants to go to their countries, and then closed and not be opened to to allow them to return back, which would be a relief to the citizens of South Africa

\section{Stereotyping}

Stereotyping was echoed in most comments as migrants were grouped into a certain class different from that of local citizens in their address. Migrants were stereotyped as poor and a threat to locals' jobs. The negative attitude towards migrants can be observed in the hate speech, the negativeother representations and discrimination.

However, there were others who showed respect for humanity regardless of nationality, who sympathised with the situation experienced at the border and felt that no human being deserved to experience such challenges and frustrations. These comments that showed empathy were met with negative reproach in some aspects. Other individuals expressed their awareness of socioeconomic realities by highlighting how much migrants contributed towards the socioeconomic development of the nation hence the need to unite and stand as one. They also emphasised on how migrants also benefit the economy and hence are not taking from the economy. Some of the comments between migrants and SA native nationals resembled a war zone as harsh words were exchanged and this revealed the differences that still exist between the two groups, echoing the views of Garba (2020) and Masuku (2020).

\section{Conclusion}

Negative attitudes and hate towards migrants are still evident in SA and discourse plays a role in their continued 
existence. Although the government has amended their policies to promote locals first through affirmative action and employment equity acts, beliefs are still held amongst individuals that migrants are the reason behind unemployment and scarcity of resources in SA. There is need for the government and policymakers to raise awareness with regard to such issues through their policy implementations and work policies on the clear criteria that result in employment of migrants in the absence of local qualified personnel. Awareness should also be raised about human rights and the rights to humanity, which everyone should understand and respect. As discourse plays a role in the enactment or reproduction of these attitudes, using the platforms that the majority familiarise with to raise this awareness on oneness, unity and respect for humanity can be one way to dispel negative perceptions and attitudes held in the minds of people one step at a time. This will in turn allow for a smooth flow in implementation of local government policies and benefit from the diverse opportunities presented by locals and migrants, as issues are addressed in a holistic manner.

\section{Acknowledgements Competing interests}

The authors declare that they have no financial or personal relationship(s) that may have inappropriately influenced them in writing this article.

\section{Authors' contributions}

V.S.R. contributed towards the conceptualisation of the article, research methodology, formal analysis and the writing of the original draft S.Z. contributed towards the conceptualisation, supervision and writing-review and editing of the article.

\section{Funding information}

This article did not receive any specific grant from any funding agency in the public, commercial or not-for-profit sectors.

\section{Data availability}

The data will be available on the link provided from the journal publishers.

\section{Disclaimer}

The views and opinions expressed in this article are those of the authors and do not necessarily reflect the official policy or position of any affiliated agency of the authors.

\section{References}

Adam, H. \& Moodley, K., 2013, Imagined liberation: Xenophobia, citizenship and identity in South Africa, Germany and Canada, SUN PRESS, Stellenbosch.

African Centre for Migration \& Society, 2020, Fact sheet on foreign workers in South Africa: Overview based on statistics South Africa data (2012-2017), African Centre for Migration \& Society, Johannesburg, viewed 03 February 2021, from http:// www.migration.org.za/fact-sheet-onforeign-workers-in-south-africa-overviewbasedon-statistics-south-africadata-2012-2017/.
'Briefing: South Africa's “Afrophobia” problem', The New Humanitarian, March, 2020, viewed 13 August 2021, from https://www.thenewhumanitarian.org/newsfeature/2020/03/11/south-africa-xenophobia-migrants-refugees-afrophobia.

Business Insider South Africa, 2020, UIF Covid-19 payout trouble: These are the most common problems holding back the cash, Business Insider South Africa, viewed 29 January 2021, from https://www.businessinsider.co.za/how-toavoid-uif-problems-2020-5.

Carter, D., 2010, Tolerance in South Africa: Exploring popular attitudes towards foreigners, Afrobarometer Briefing Paper No. 82.

Choane, M., Shulika, L.S. \& Mthombeni, M., 2011, 'An analysis of the causes, effects and ramifications of xenophobia in South Africa', Insight on Africa 3(2), 129-142. https://doi.org/10.1177/0975087814411138

Consortium for Refugees and Migrants in South Africa, 2008, Protecting refugees, asylum seekers and immigrants in South Africa, Johannesburg, viewed 05 February 2021, from www.cormsa.org.za.

Cozien, C., 2015, Racism under the linguistic microscope: A preliminary investigation into what the critical analysis of South African News Media Discourse can revea about racism, stereotyping, and the relationship between culture and language. https://doi.org/10.13140/RG.2.1.4580.5528

Dicks, B., 2019, Multimodal analysis, Sage Research Fonudations, SAGE, London https:/doi.org/10.4135/9781526421036831970

Di Paola, M., 2013, A Labour perspective on xenophobia in South Africa: A case study of the Metals and Engineering industry in Ekurhuleni, MDP final report.

eNCA News, 2020, 24 December, viewed 07 February 2021, from https://www.enca. $\mathrm{com} /$ news/four-truck-drivers-died-beitbridge-border-post.

Fairclough, N., 1995, Critical discourse analysis, Longman, London.

Garba, N.W.F., 2020, Covid-19 in South Africa: Whither migrants? - African arguments, African Arguments, viewed 10 December 2020, from https://africanarguments. org/2020/06/17/covid-19-in-south-africa-whither-migrants/.

International Labour Organisation (ILO), 2013, Global employment trends, viewed 05 February 2021, from http://www.ilo.org/wcmsp5/groups/public/-dgreports/---dcomm/---publ/documents/publication/wcms_202326.pdf.

International Labour Organisation (ILO), 2019, Global and continental policy frameworks, Guiding Labour Migration and Labour Mobility in Africa, viewed 26 February 2021, from https://www.ilo.org/wcmsp5/groups/public/---africa/ documents/publication/wcms_673552.pdf.

International Organization for Migration, 2009, March 10, 'ONE' movement launched to combat xenophobia and racism in South Africa as new study is released, viewed 04 October 2021, from https://www.iom.int/news/one-movement-launchedcombat-xenophobia-and-racism-south-africa-new-study-released.

International Organization for Migration, 2019, Glossary on migration, IML Series No. 34, International Organization for Migration, Switzerland.

IOL News, 2020, 'Xenophobic South Africans can't champion \#BlackLivesmatterMalema', 08 June, viewed 08 February 2021, from https:www.iol.co.za/news/ politics/xenophobic-south-africans-cant-champion-blacklivesmattermalema-49122760.

Kress, G. \& Van Leeuwen, T., 2001, Multimodal discourse: The modes and media of contemporary communication, Arnold, London.

Masuku, S., 2020, 'How South Africa is denying refugees their rights: What needs to change', The Conversation, viewed 03 February 2021, from https://theconversation. com/how-southafrica-is-denying-refugees-their rights-what-needs-to-change-135692.

Mukumbang, F.C., Ambe, A.N. \& Adebiyi, B.O., 2020, 'Unspoken inequality; how COVID-19 has exacerbated existing vulnerabilities of asylum-seekers, refugees and undocumented migrants in South Africa', International Journal for Equity in Health 19, 141. https://doi.org/10.1186/s12939-020-01259-4

NewzRoom Afrika, 2021, 'NewzRoom Afrika's Pelane Phakgadi is in Beitbridge for the latest developments there', 06 January, viewed 04 February 2021, from https:// www.youtube.com/watch?v=xk u dO5ZrM.

Office of the United Nations High Commissioner for Refugees, 2013, Global trends 2012: Displacement: The new 21st century challenge, viewed 04 February 2021 from http://unhcr.org/globaltrendsjune2013/UNHCR GLOBAL TRENDS 2012 V08_web.pdf.

Peberdy, S., n.d., Setting the scene: Migration and urbanisation in South Africa: Synthesis report, The Atlantic Philanthropies, Johannesburg.

Richardson, J.E., 2007, Analysing newspapers - An approach from critical discourse analysis, Palgrave Macmillan, Hampshire.

SABC News, 2020a, 'Truck drivers once again protest the employment of foreign nationals, forcing the closure of a major Cape Town highway', 07 July, viewed 07 February 2021, from https://www.youtube.com/watch?v=p01dDpQdZPA.

SABC News, 2020b, 'Discussion on bottleneck at the border post', 25 December, viewed 07 February 2021, from https://www.youtube.com/watch?v=mDsckyzn4o.

SABC News, 2020c, 'Truck drivers frustrated as they remain stuck at the border', 25 December, viewed 07 February 2021, from https://www.sabcnews.com/sabcnews/ truck-drivers-frustrated-as-they-remain-stuck-at-beitbridge-border/?fbclid=IwARO qrXcRvcAwjMV8IKTjfOdKy7M3_7w2-4anJJLD_dw6PewrRXbqjBcnCps.

SABC News, 2020d, 'Calls for intervention at the Beitbridge border as several die in congestion', 26 December, viewed 07 February 2021, from https://www. youtube.com/watch?v=pCUX5vSTyUg

SABC News, 2021, 'Cross border travel: Thousands stuck at Beitbridge waiting to cross into SA', 06 January, viewed 07 February 2021, from http://ow.ly/M6cm50D1gDn. 
Schippers, C.S., 2015, Attitudes towards foreigners in South Africa: A longitudinal study, viewed 09 February 2021, from https://scholar.sun.ac.za.

South Africa's Diverse Culture Artistic and Linguistic Heritage, 2020, SAHO@20 (South African History Online), viewed 09 February 2021, from https://www. sahistory.org.za/article/south-africas-diverse-culture-artistic-and-linguisticheritage.

Stephan, W.G., Ybarra, O. \& Morrison, K.R., 2009, 'Intergroup threat theory', in T.D. Nelson (ed.), Handbook of prejudice, stereotyping, and discrimination, p. 44, Psychology Press, Taylor and Francis Group, Hononlulu.
Stephan, W.G. \& Stephan, C.W., 2000, 'An integrated threat theory of prejudice', in S. Oskamp (ed.), Reducing prejudice and discrimination, pp. 23-45, Lawrence Erlbaum Associates, Mahwah, NJ.

The World Bank, 2018, New study finds immigrants in South Africa generate jobs for locals, viewed 26 February 2021, from https://www.worldbank.org/en/country/ southafrica/publication/new-study-finds-immigrants-in-south-africa-generatejobs-for-locals.

Van Dijk, T.A., 2006, Principles of critical discourse analysis, University of Amsterdam, Amsterdam. 